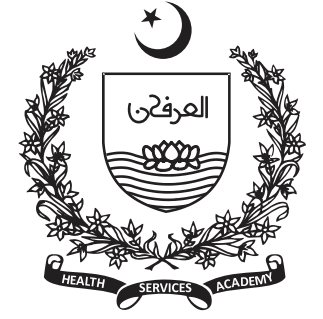

${ }^{1}$ Assistant Professor

Nishtar Institute of

Dentistry Multan

${ }^{2}$ Associate Professor Institute of Dentistry CMH Lahore

${ }^{3}$ Associate Professor Multan Medical \& Dental College Multan

${ }^{4}$ Assistant Professor Multan Medical \& Dental College Multan

${ }^{5}$ Demonstrator School of Dentistry SZABMU Islamabad

6Senior Lecturer Multan Medical \& Dental College Multan

Corresponding Author:

Talha Ashar

Email:

talhatheoperativedentist@g mail.com

\section{Parent's Knowledge and Awareness in Maintaining their Children's Oral Health: A Cross Sectional Survey}

Talha Ashar ${ }^{1}$, Asma Shakoor ${ }^{2}$, Mustafa Sajid ${ }^{3}$, Rabia Zafar ${ }^{4}$, Mohsin Javaid5, Javeria Afzal ${ }^{6}$

\begin{abstract}
Background: Parents had a great role in prevention of child's dental decay and special emphasis has been put on the maintenance of child oral hygiene status for achieving optimum health as early childhood caries is regarded as the major dental disease around the world. Our study aimed to evaluate knowledge and awareness of the parents regarding oral hygiene of the children.
\end{abstract}

Methods: A descriptive cross-sectional study was conducted from March 2019 to August 2019 in Nishtar Institute of dentistry, Multan. Total 300 parents of 4 to 9-year-old children were enrolled in the study. Detailed demographics including age, education, and monthly income were recorded. The questionnaire regarding oral health was designed and data was collected through that self-administered questionnaire. Data was analysed by SPSS 24.0.

Results: About $7 \%$ of Parent's were uneducated, $38.5 \%$ got the school education, $15.5 \%$ got the college education and $39 \%$ got the university education. Only $32 \%$ parents were aware of proper brushing technique while $68 \%$ were unaware. $56 \%$ parents said that the sweets, chocolates and junk food are not good for oral health while $44 \%$ denied this. $46 \%$ parents told that their children complained about teeth and $42 \%$ parents visited the dentist for their children.

Conclusions: There is a need to improve the knowledge and practices of parents and children about the oral hygiene maintenance to aid in reducing the oral health problems in future.

Keywords: Educational Level, Brushing technique, Parents, Oral health

\section{Introduction}

$\mathrm{V}$

A key component of prevention from oral disease is the knowledge and understanding of parents of their children's oral health, which contributes to the development of their children's safe oral health (1). Moreover, parents' lack of education and oral health literacy will also impact their children's future buoyancy behaviours and attitudes towards adulthood $(2,3)$. A lack of parental knowledge has been reported to represent a significant predictor of poor oral hygiene for children (4). Their primary medical practitioners, dentists, friends and relatives typically give parents oral health advice. Parents normally ask questions about the time of teeth eruption, dental duration and tooth brushing frequency, fluoride toothpaste use and diet and sugar consumption. (5) parents often ask specific questions. Dental caries was reported to be higher among children whose parents lacked oral health awareness and knowledge (6). Parents have been previously 
researched on the knowledge and understanding of oral health of infants. Many studies of poor parents' knowledge and understanding of oral health have been reported to developing countries (7-8). However, the reverse was revealed in other studies from developed countries (9-10).

Both parents' knowledge and behaviour play a key role in preserving healthy teeth for children who need support and encouragement in carrying out daily oral hygienic measurements, such as tooth burning, the use of dental floss and body rinses after eating and snacking. Family attitudes develop self-esteem, trust and daily tooth brushing practices (11). There have been low educational and social requirements that cause the development of different dental illnesses and teeth losses in children at an early age (12).

In the developed countries, numerous research papers on this subject have been published. In Pakistan, however, very few studies were conducted mainly on the education of parents. The objective/aim of this study is to evaluate the impact of parents' education level upon the development of dental diseases and to assess the condition of child dental health for ensuring prevention and early treatment of dental caries.

\section{Methodology}

A descriptive cross sectional study was conducted at Nishtar Institute of dentistry, Multan during from the period March 2019 to August 2019. Total 300 parents of 4 to 9-year-old children were enrolled in the study. Detailed demographics including age, education, and monthly income were recorded. Informed consent was taken from the participants before the data collection. For illiterate patients, data collector explained questions to the patients and transferred the answers to the questionnaire. Those parents of children having age less than 4 years and above 9 years were excluded from this study.

Pre-designed parental questionnaires were used to collect relevant information from parents. The questionnaire was revalidated by five senior members of faculty of different dental colleges, which included Professors and Associate professors. They were requested to assess all items of the questionnaire on the basis of relevance, content, language and cultural acceptance .The forms from all faculty members were collected and their responses were analyzed. Some minor variations were suggested in the language of a few items based on the locally popular words.
Questionnaire includes questions about habits of their children regarding consumption of sweets, chocolates, junk foods and cold drinks. Few questions related to the knowledge of parents regarding proper brushing technique, effects of sweets and cold drinks. The questionnaires were checked on routine basis in order to complete the missing data. All the data was analyzed by SPSS 24.0.

\section{Results}

A total of 300 parents participated with their children in this study and their data was then considered for the analysis. We found that $21(7 \%)$ of parent's were uneducated, $116(38.67 \%)$ got the school education, 46 $(15.33 \%)$ got the college education and $117(39 \%)$ got the university education. (Figure 1)

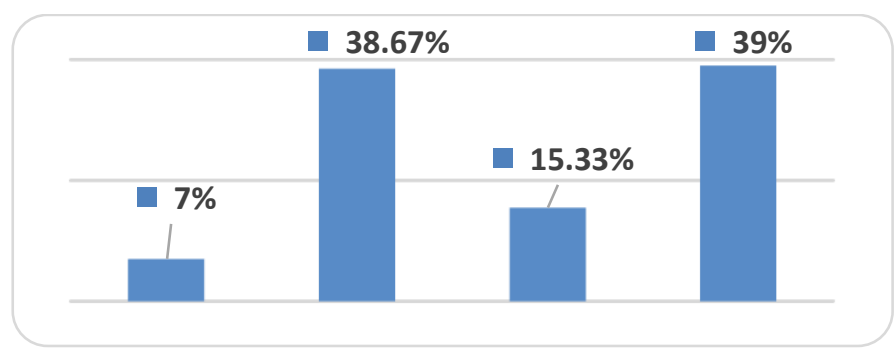

Figure 1. Education level of all the participants

Regarding the habits of consumption of sweets, chocolates, junk foods and cold drinks, 30\% parents said that their children usually take it once a day, $28 \%$ parents were used to give them twice a day, $2 \%$ parents give their children rarely and $40 \%$ parents said that their children are used to take sweets every chance which he/she gets as shown in figure 2 .

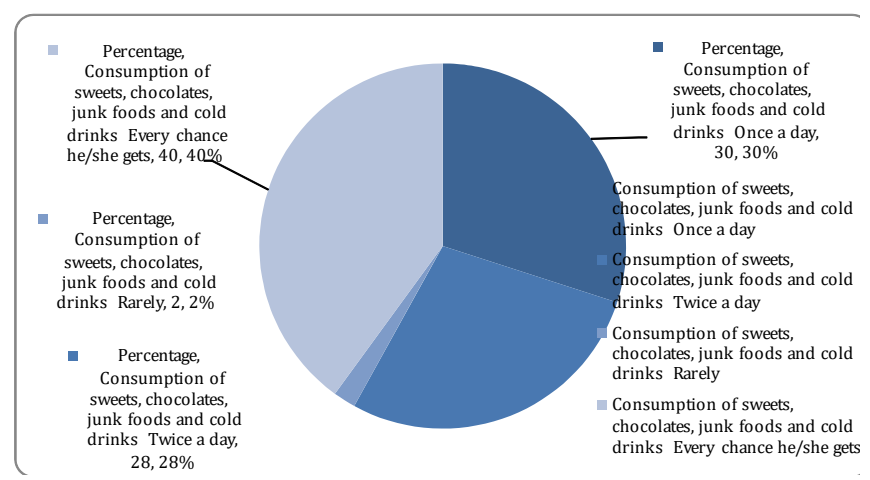

Figure 2. Consumption of sweets, chocolates, junk foods and cold drinks 
There were few questions related to the knowledge of parents regarding proper brushing technique, effects of sweets and cold drinks. Only $32 \%$ parents were aware of proper brushing technique while $68 \%$ were unaware. $56 \%$ parents said that the sweets, chocolates and junk food are not good for oral health while $44 \%$ denied this. $46 \%$ parents told that their children complained about teeth and $42 \%$ parents visited the dentist for their children. as shown in table 1.

Table 1. Knowledge of parents regarding proper brushing technique, effects of sweets and cold drinks

\begin{tabular}{|l|l|c|}
\hline \multicolumn{2}{|l|}{ Variable name with category } & Percentage \\
\hline \multirow{2}{*}{$\begin{array}{l}\text { Knowledge about the brushing } \\
\text { techniques }\end{array}$} & Yes & 32 \\
\cline { 2 - 3 } & No & 68 \\
\hline \multirow{2}{*}{$\begin{array}{l}\text { Effect of sweets, chocolates, junk foods } \\
\text { and cold drinks on Teeth }\end{array}$} & Yes & 56 \\
\cline { 2 - 3 } & No & 44 \\
\hline \multirow{2}{*}{ Ever Complaint about teeth } & Yes & 46 \\
\cline { 2 - 3 } & No & 54 \\
\hline Ever taken your child to a dentist & Yes & 42 \\
\cline { 2 - 3 } & No & 58 \\
\hline
\end{tabular}

\section{Discussion}

The rationale of this study is to improve the knowledge and to motivate the parents and their children regarding their oral and dental health and treatment needs. After the data collection and analysis we came to know that the parents are lacking in basic knowledge about the dental health that's why we have to think and plan in a systematic way to provide education about dental health and knowledge to maintain oral hygiene to the general public and children. In developing countries, the data found regarding oral health is less comparable to the data collected from developed countries due to poverty, illiteracy and lack of oral health education and counselling (13).

Our study results indicate that most parents, i.e. $68 \%$, did not know what brushing technique was correct, which is closely like S. Priyanka (66\%) findings which is mainly due to the fact that there are no efforts taken to educate the parents regarding oral health (14). It is normal in this study that among parents' mothers have more in-growth interest in their children than fathers because of less concern of their fathers, however due to the lack of awareness mothers are unable to lead their children to good oral health (15). Regarding the consumption of sweets, chocolates etc mostly parents said that their children want to consume the sweets whenever its available and they can get the chance to eat (16).56\% parents were aware that sweets, chocolates and junk food are not good for oral health while $44 \%$ denied this evidence. Insufficient parental education leads to poor dietary habits of their children and unhealthy lifestyle $(17,18$, 19).

$46 \%$ of the parents showed that their children complained about dental issues and only $42 \%$ of the parents with their children visited their dentists after the problem had emerged otherwise, they are not used to visit the dentist for regular checkups (20).

In the present study 32-56 percent of the highly educated parents know about oral hygiene measures for the children in Lithuania, while the oral hygiene measures for the children are killed by between 37 and 41 percent of educated parents (21).

$32 \%$ of parents in the present study knew about dental brushing, while $25.4 \%$ of parents in an Indian study knew tooth brushing.22Gussy et al reported that 95\% of the parents in Australia knew their children would be able to brush the first tooth. In developing countries, well-structured community awareness projects have greatly changed the awareness of parents in the under-developed countries23. In the current survey, $56 \%$ of parents knew that diet had an effect on oral hygiene, while only $70 \%$ of parents know this in Indian studies $(22,24)$. In this study, only $56 \%$ of parents know sweats and chocolate are in accordance with their children's dental health.

Just $42 \%$ of parents visited the dentist in our sample, while Zarvas et al. reported that $53 \%$ of parents bought their children from the dentist25. Randomized control studies have shown that dental visits have greatly increased parent awareness of children's dental health26. Wyne et al. reported that 34.2 percent of parents in Saudia visited the dentists for their children. The finding in this research shows that there is a need for the community and school-based programs to change the perception, improve the knowledge and practices of parents and children about the oral hygiene maintenance to aid in reducing the oral health problems in future.

\section{Conclusion}

This study indicates the lack of awareness among parents and their children regarding oral hygiene maintenance. The active participation of parents is significant. It is essential for the dentist to acknowledge the importance of parent's role and children themselves as a root of the growing 
population so that it will help them in developing a positive attitude towards oral hygiene. Along with this regular check-ups should be done to assess the oral hygiene.

\section{Conflict of interest:}

The authors declare that there is no conflict of interest. This study was not funded by any organization or institute.

\section{References}

1. Okada M, Kawamura M, Kaihara Y, et al. Influence of parents' oral health behaviour on oral health status of their school children: An exploratory study employing a causal modelling technique. Int J Paediatr Dent 2002; 12(2): 101-8. (http://dx.doi.org/10.1046/j.1365263X.2002.00338.x)

2. Sehrawat P, Shivlingesh KK, Gupta B, Anand R, Sharma A, Chaudhry M. Oral health knowledge, awareness and associated practices of preschool children's mothers in Greater Noida, India. Niger Postgrad Med J 2016; 23(3): 152-7.

3. Guidelines on Oral Healthcare for Pre-School Children. Oral Health Division Ministry of Health Malaysia. https://www.mah.se/upload/

FAKULTETER/OD/Avdelningar/who/WPRO/Malay sia/data/oral_healthcare_for_the_pre-

school_children.pdf

4. Vanagas G, Milasauskiene Z, Grabauskas V, Mickeviciene A. Associations between parental skills and their attitudes toward importance to develop good oral hygiene skills in their children. Medicina (Kaunas) 2009; 45(9): 718-23.

5. Felton A, Chapman A, Felton S. Basic Guide to oral health education and promotion, 2 nd ed. john wiley \& sons, Ltd, The Atrium, Southern Gate, Chichester, West Sussex, PO19 8SQ, UK.

6. Amin TT, Al-Abad BM. Oral hygiene practices, dental knowledge, dietary habits and their relation to caries among male primary school children in Al Hassa, Saudi Arabia. Int J Dent Hyg 2008; 6(4): 361-70.

7. Leo Bernard Manuel M, Gheena S. Awareness of oral care and brushing technique in children below 5 years of age administered to parents. J Pharm Sci Res 2015;7:577-8

8. Nazari Z, Taherpour M. mothers' Awareness, regarding orodental health of their children at age of 16 years old in Shirvan. J North Khorasan Univ Med Sci 2013; 5: 97986.

9. Prabhu A, Rao AP, Reddy V, Ahamed SS, Muhammad $S$, Thayumanavan S. Parental knowledge of pre-school child oral health. J Community Health 2013; 38(5): 880-4.
10. Alyahya L. Parental knowledge and practices regarding their children's oral health in Kuwait. Eur J Paediatr Dent 2016; 17(4): 267-73

11. G. Vanagas, Ž Milašauskienè, V. Grabauskas, A. Mickevičienè.Associations between parental skills and their attitudes toward importance to develop good oral hygiene skills in their children.Medicina (Kaunas) 2009;45: 718-23

12. Mashoto. KO. Dental caries, oral-health-related quality of life and atraumatic restorative treatment (ART): a study of adolescents in Kilwa district of Tanzania. Centre for I Health, University of Bergen. 2011;1-6

13. Bangash RY, Khan AU, Tariq KM, Rasheed D. Evaluation of tooth brushing technique and oral hygiene knowledge. Pak Oral Dent J 2012;32:124-7.

14. S. Priyanka1, R. Mahesh2, L. Leelavathi3*Awareness and role of parents in their child's oral health and brushing technique - A questionnaire study, Drug Invention Today | Vol $10 \bullet$ Special Issue $4 \bullet 2018$

15. Kumar R, Joshi D. Awareness of dental hygiene amongst the primary school children of low socioeconomic strata. Int J ContempPediatr 2017;4:1-7.

16. runo-Ambrosius K, Swanholm G, Twetman S. Eating habits, smoking and toothbrushing in relation to dental caries: a 3-year study in Swedish female teenagers. Int J Paediatr Dent 2005;15:190-6.

17. Jürgensen N, Petersen PE. Oral health and the impact of socio-behavioural factors in a cross sectional survey of 12- year old school children in Laos. BMC Oral Health 2009;9:29.

18. Marshall TA, Eichenberger-Glilmore JM, Broffitt BA, Warren JJ, Levy SM. Dental caries and childhood obesity: roles of diet and socioeconomic status. Community Dent Oral Epidemiol 2007;35:449-58.

19. Johnson B, Hackett AF. Eating habits of 11-14-year-old schoolchildren living in less affluent areas of Liverpool, UK. J Hum Nutr Diet 1997;10:135-44.

20. Al-Zahrani AM, Al-Mushayt AS, Otaibi MF, Wyne AH. Knowledgeand attitude of Saudi mothers towards their preschool children's oral health. Pak J Med Sci 014;30:720-4.

21. Saldūnaitė $K$, Bendoraitienè EA, Slabšinskienė E, Vasiliauskienè I, Andruškevičienè V, Zūbienè J. The role of parental education and socioeconomic status in dental caries prevention among Lithuanian children. Medicina. 2014 Jan 1;50(3):156-61.

22. Suresh BS, Ravishankar TL, Chaitra TR, Mohapatra AK, Gupta V. Mother's knowledge about pre-school child's oral health. Journal of indian society of pedodontics and preventive dentistry. 2010 Oct 1;28(4):282

23. Gussy MG, Waters EB, Riggs EM, Lo SK, Kilpatrick NM. Parental knowledge, beliefs and behaviours for oral health of toddlers residing in rural Victoria. Aust Dent J 2008;53:52-60. 
24. Kumar RP, John J, Saravanan S, Arumugham IM. Oral health knowledge, attitudes and practices of patients and their attendants visiting College of Dental Surgery, Saveetha University, Chennai. J Indian Assoc Public Health Dent 2009;13:43-53.

25. Zavrsa AI, Vrahopoulos T, Souliotis K, Silvestros S, Vrotsos J. Oral health knowledge of Greek navy recruits and their socio economic determinants. BMC Oral Health 2002;2:12-8
26. Blinkhorn AS, Gatrix D, Holloway PJ, WainwrightStringer YM, Ward SJ, Worthington HV. A cluster randomized control trial of the value of dental educators in general practice. Br Dent J 2003;195:395-400

27. Wyne AH, Chohan AN, Al-Qedrah A. Oral health knowledge and sources of information among male secondary school children in Riyadh. Saudi Dent J 2005; 17:140-45. 